\title{
The control of porosity at nano scale in resorcinol formaldehyde carbon aerogels
}

\author{
Mojtaba Mirzaeian · Peter J. Hall
}

\begin{abstract}
Organic aerogels were synthesized by sol-gel polymerization of resorcinol $(\mathrm{R})$ with formaldehyde $(\mathrm{F})$ catalyzed by sodium carbonate (C) followed by vacuum drying. The influence of the resorcinol/sodium carbonate ratio $(\mathrm{R} / \mathrm{C})$ on the porous structure of the resultant aerogels was investigated. The nitrogen adsorption-desorption measurements show that the aerogels possess a well developed porous structure and mesoporosity was found to increase with increasing the $\mathrm{R} / \mathrm{C}$ ratio. Carbon aerogels were obtained by carbonization of RF aerogels. The carbonization temperature impacts the microstructure of the aerogels by pore transformations during carbonization probably due to the formation of micropores and shrinkage of the gel structure. The results showed that a temperature of $1073 \mathrm{~K}$ is more effective in the development of the pore structure of the gel. Activated carbon aerogels were obtained from the $\mathrm{CO}_{2}$ activation of carbon aerogels. Activation results in an increase in the number of both micropores and mesopores, indicative of pore creation in the structure of the carbon. Activation at higher temperatures results in a higher degree of burn off and increases the pore volume and the surface area remarkably without change of the basic porous structure, pore size, and pore size distribution.
\end{abstract}

\section{Introduction}

The control of the porous structure of carbon is of practical interest for different applications such as adsorbents for gas separation [1, 2], electrode materials for energy storage [3-5], catalyst supports [6], packing materials for chromatography [7], host materials for gas storage[8], thermal and/or phonic insulators $[9,10]$, etc. For many advanced applications such as double layer supercapacitors the control of porosity at nano-level is very essential.

Resorcinol formaldehyde (RF) aerogels are special type of highly cross-linked aromatic polymers with a high pore volume $\left(0.25-1.25 \mathrm{~cm}^{3} / \mathrm{g}\right) \quad[11]$, low density (0.06$\left.0.103 \mathrm{~g} / \mathrm{cm}^{3}\right)$ [12], large specific surface area $(400$ $1000 \mathrm{~m}^{2} / \mathrm{g}$ ) [13], and mostly amorphous structure [14]. The morphology of RF aerogels can be modified as a function of different synthesis parameters. This characteristic allows the tailoring of the internal structure of these porous materials on a nanometer scale and makes them particularly well suited for a variety of applications. $\mathrm{RF}$ aerogels can be used as precursors for the preparation of porous carbons with similar appearance and macrostructure, but having slight differences in microstructure. Carbon aerogels are a special class of hard carbons with a low degree of order [14] prepared via the pyrolysis of organic aerogel precursors at elevated temperatures under inert atmospheres. The properties of carbon aerogels can be engineered by a proper choice of carbonization and activation conditions, but the structure of carbonaceous precursors significantly influences the final product [15].

The synthesis of RF aerogels consists of a polycondensation reaction mechanism between resorcinol and formaldehyde which is analogous to the mechanisms for the synthesis of inorganic sol-gels like silica or titanium based systems [16]. There have been few systematic studies that relate carbon production parameters, such as synthesis condition, carbonization and activation conditions to the pore structure of the final carbon. 


\section{Experimental}

\section{Chemicals}

Resorcinol $\left[\mathrm{C}_{6} \mathrm{H}_{4}(\mathrm{OH})_{2}\right.$, Sigma-Aldrich, 98\%], formaldehyde [(HCHO), Sigma-Aldrich, 37\% solution], sodium carbonate anhydrous $\left[\mathrm{Na}_{2} \mathrm{CO}_{3}\right.$, Sigma-Aldrich, $\left.\geq 99.5 \%\right]$, acetone [Fisher Scientific, reagent grade].

RF aerogel synthesis

RF hydrogels were synthesized by the polycondensation of resorcinol $\left[\mathrm{C}_{6} \mathrm{H}_{4}(\mathrm{OH})_{2}\right](\mathrm{R})$ with formaldehyde [HCHO] (F) according to the method proposed by Pekala and coworkers $[17,18]$. RF solutions were prepared by mixing the required amount of $(\mathrm{R}),(\mathrm{F})$, and sodium carbonate $(\mathrm{C})$ and distilled water $(\mathrm{W})$ under vigorous stirring for $45 \mathrm{~min}$. The molar ratio of $\mathrm{R}$ to $\mathrm{F}(\mathrm{R} / \mathrm{F})$ and ratio of $\mathrm{R} / \mathrm{W}(\mathrm{g} / \mathrm{mL})$ were constant and the molar ratio of $R$ to $C(R / C)$ was varied. The homogeneous $\mathrm{RF}$ solutions were poured into sealed glass vials to prevent the evaporation of water during gelation and gelled by aging for $72 \mathrm{~h}$ at $363 \mathrm{~K}$ into an oven to obtain RF hydrogels. The hydrogels at this point are saturated with water. To remove water from their structure, the gels were solvent exchanged by immersing in acetone for 3 days prior to the vacuum drying. Finally, the hydrogels were dried in a vacuum oven at $353 \mathrm{~K}$ for 3 days.

TGA analysis of aerogels

Thermogravimetric analysis (TGA) was used to determine the carbonization conditions for the dried aerogels. The thermal analysis system for analysis of aerogel samples was a Mettler TGA/DSC system. Typically between 5-10 mg of the gel was weighed in an alumina pan and placed on the horizontal microbalance connected to the TGA. This weight corresponded to a weight percent of $100 \%$ for sample. The sample was purged with Ar flowing at $50 \mathrm{~mL} / \mathrm{min}$ for $30 \mathrm{~min}$ at $303 \mathrm{~K}$ to remove oxygen from the system. It was then heated to $1273 \mathrm{~K}$ at $10 \mathrm{~K} / \mathrm{min}$ under $\mathrm{Ar}$ and the variation of the weight loss with temperature was determined.

\section{Preparation of carbon aerogels}

To study the effect of carbonization temperature on the porous structure of carbon aerogels, carbonization of the dried RF aerogels was performed at different temperatures in a tubular furnace using the following method: 3 grams of dried gel was used in each carbonization experiment. The gel was placed in a ceramic boat and purged with $\mathrm{Ar}$ flowing at $200 \mathrm{~mL} / \mathrm{min}$ for $30 \mathrm{~min}$ at room temperature prior to the heating program. The furnace was heated to $423 \mathrm{~K}$ at $5 \mathrm{~K} / \mathrm{min}$ and maintained at $423 \mathrm{~K}$ for $30 \mathrm{~min}$.
Then it was heated to $673 \mathrm{~K}$ at $5 \mathrm{~K} / \mathrm{min}$ and held for $30 \mathrm{~min}$. It was then heated to the final carbonization temperature at $10 \mathrm{~K} / \mathrm{min}$ and kept for $3 \mathrm{~h}$. The whole heating program was performed under Ar flowing at $200 \mathrm{~mL} / \mathrm{min}$. After carbonization, the furnace was cooled in flowing $\mathrm{Ar}$ to room temperature.

Activation of carbon aerogels

The activated carbon aerogels were prepared by oxidation of the carbon aerogels under $\mathrm{CO}_{2}$ at different temperatures. A sample of carbon aerogel was placed in a ceramic boat at the center of the tubular furnace and purged with $\mathrm{Ar}$ flowing at $200 \mathrm{~mL} / \mathrm{min}$ for $30 \mathrm{~min}$ prior to heating. The sample was heated to the appropriate activation temperature at $10 \mathrm{~K} / \mathrm{min}$. At this stage gas was changed to $\mathrm{CO}_{2}$ and the sample was kept at the activation temperature under $\mathrm{CO}_{2}$ for varying time. It was then cooled down to room temperature under Ar flowing at $200 \mathrm{~mL} / \mathrm{min}$.

\section{Sample characterization}

The porosity of RF aerogels and carbon aerogels were studied by the analysis of nitrogen adsorption-desorption isotherms measured by an ASAP 2420 adsorption analyzer (Micromeritics) at $77 \mathrm{~K}$. The samples were evacuated at $373 \mathrm{~K}$ for $2 \mathrm{~h}$ prior to the adsorption measurements. BET method was used for surface area measurements, BJH adsorptions-desorption was used for mesopore analysis, and $t$-plot method was used for micropore analysis. Total pore volume was calculated from the adsorbed volume of nitrogen at $P / P_{0}=0.99$ (saturation pressure). Pore size distributions were obtained by the $\mathrm{BJH}$ method from adsorption branch of the isotherms [19].

\section{Results and discussion}

Surface characterization of aerogels

Figure 1 shows nitrogen adsorption-desorption isotherms at $77 \mathrm{~K}$ for $\mathrm{RF}$ aerogels prepared at different $\mathrm{R} / \mathrm{C}$ ratios. All isotherms are type IV showing adsorption hysteresis which indicates the presence of mesopores [19].

For samples with $\mathrm{R} / \mathrm{C}=100$ and 200 the initial region of the isotherms experiences a sharper rise at low $P / P_{0}$ which indicates the presence of micropores in addition to mesopores in the gel structure.

Hysteresis loops for gels with $\mathrm{R} / \mathrm{C}=500$ and 600 in the $P / P_{0}$ range $0.2-1.0$ show that mesoporosity is dominant in their structures. The lower part of the hysteresis loops represent the filling of the mesopores while the upper parts represent the emptying of the mesopores [19, 20]. It can be 


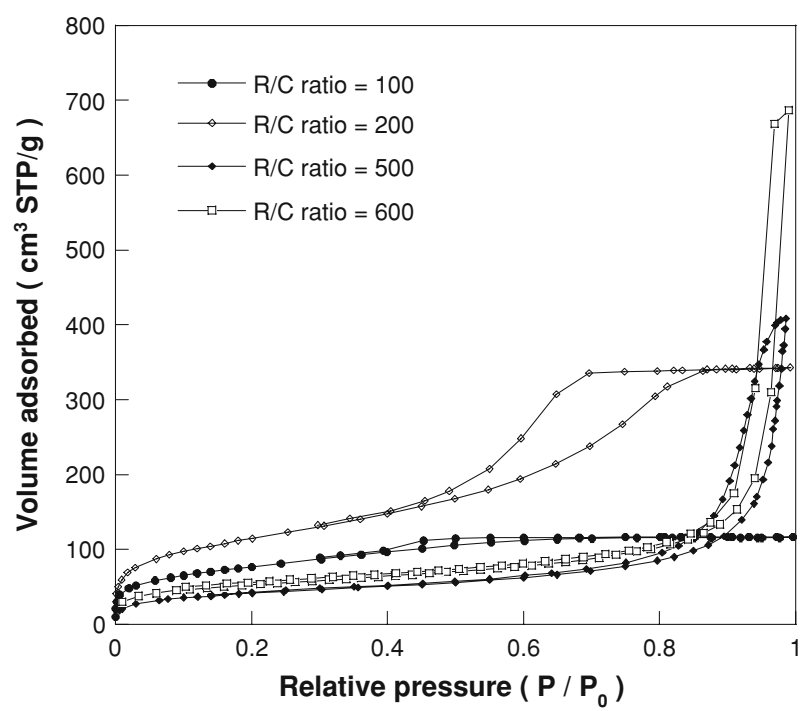

Fig. $1 \mathrm{~N}_{2}$ adsorption/desorption isotherms at $77 \mathrm{~K}$ for gels with various $\mathrm{R} / \mathrm{C}$ ratios

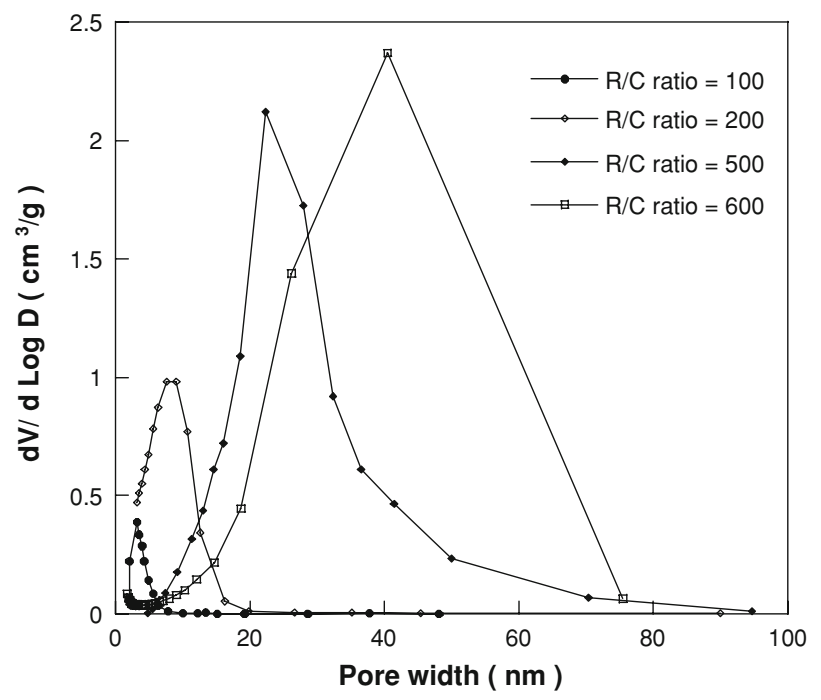

Fig. 2 Pore size distribution of RF gels with various R/C ratios

seen that the isotherms are shifted to the right at higher relative pressures with increase in $\mathrm{R} / \mathrm{C}$ ratio. This indicates the development of mesoporosity and formation of larger mesopores during gelation process at higher $\mathrm{R} / \mathrm{C}$ ratios.
The pore size distribution (PSD) of RF gel samples are shown in Fig. 2. The sample with $\mathrm{R} / \mathrm{C}=100$ shows the narrowest PSD with a maxima around pores of $2 \mathrm{~nm}$ diameter. For the sample with $\mathrm{R} / \mathrm{C}=200$ the PSD is wider and the maxima is shifted to pores of $7 \mathrm{~nm}$ diameter. For samples with $\mathrm{R} / \mathrm{C}=500$ and 600 the pore size distribution curves are even wider and show that the maxima are shifted to the right and located around 22 and $40 \mathrm{~nm}$, respectively. This shows the relationship between mesoporous structure and $\mathrm{R} / \mathrm{C}$ ratio clearly. The data in Table 1 show a significant increase in total pore volume and mesopore volume when $\mathrm{R} / \mathrm{C}$ ratio increases from 100 to 600 . The mean pore size markedly increases with the $\mathrm{R} / \mathrm{C}$ ratio.

Tamon et al. have shown that during the polycondensation process, resorcinol and formaldehyde are consumed to form highly cross-linked particles. The aggregated particles become interconnected after gelation showing a structure composed of rings of particles with 20-50 particles per ring [21]. The particle size ranges from 3 to $20 \mathrm{~nm}$ and increases with $\mathrm{R} / \mathrm{C}$ ratio [12]. Therefore the $\mathrm{R} / \mathrm{C}$ ratio is the principal parameter that controls the size of interconnected particles leading the scale and size of pores in the gel structure.

Effect of carbonization conditions on the porous structure of the gels

Figure 3 shows adsorption and desorption isotherms of nitrogen at $77 \mathrm{~K}$ on RF001 aerogel and CRF001 carbon aerogels carbonized at different temperatures.

Adsorption-desorption isotherms suggest that the amount of nitrogen adsorbed by carbon aerogels increases with increase in the carbonization temperature for $T \leq 1073 \mathrm{~K}$. These results mean that pore volume of carbon gels increases with increasing the temperature in this range. As the carbonization temperature increases to $1073 \mathrm{~K}$, carbonization process modifies the porous structure of the original gel and creates more micropores in the structure by releasing volatile matters during carbonization. Evidence for this comes from the sharp rise at the initial region of the isotherms $\left(P / P_{0}<0.01\right)$ which is indicative of the presence of micropores in carbon aerogels.

Figure 3 also shows that for the carbonization temperature above $1073 \mathrm{~K}$, the amount of nitrogen adsorbed by

Table 1 Porous characteristics of RF aerogels

\begin{tabular}{|c|c|c|c|c|c|c|c|c|c|c|}
\hline Samples & $\mathrm{R} / \mathrm{F}$ & $\mathrm{R} / \mathrm{C}$ & $\mathrm{R} / \mathrm{W}(\mathrm{g} / \mathrm{mL})$ & $S_{\text {BET }}\left(\mathrm{m}^{2} / \mathrm{g}\right)$ & $V_{\text {total }}\left(\mathrm{cm}^{3} / \mathrm{g}\right)$ & $V_{\text {micro }}\left(\mathrm{cm}^{3} / \mathrm{g}\right)$ & $V_{\text {meso }}\left(\mathrm{cm}^{3} / \mathrm{g}\right)$ & $\% V_{\text {micro }}$ & $\% V_{\text {meso }}$ & $D_{\text {avg }}(\mathrm{nm})$ \\
\hline RF001 & 0.50 & 100 & 0.1 & 278 & 0.1797 & 0.1189 & 0.0608 & 66 & 34 & 2.58 \\
\hline RF002 & 0.50 & 200 & 0.1 & 417 & 0.5301 & 0.1801 & 0.350 & 33 & 67 & 5.10 \\
\hline RF003 & 0.50 & 500 & 0.1 & 149 & 0.632 & 0.0075 & 0.6245 & 2 & 98 & 16.96 \\
\hline RF004 & 0.50 & 600 & 0.1 & 182 & 1.0631 & 0.0132 & 1.0499 & 1.2 & 98.8 & 23.34 \\
\hline
\end{tabular}




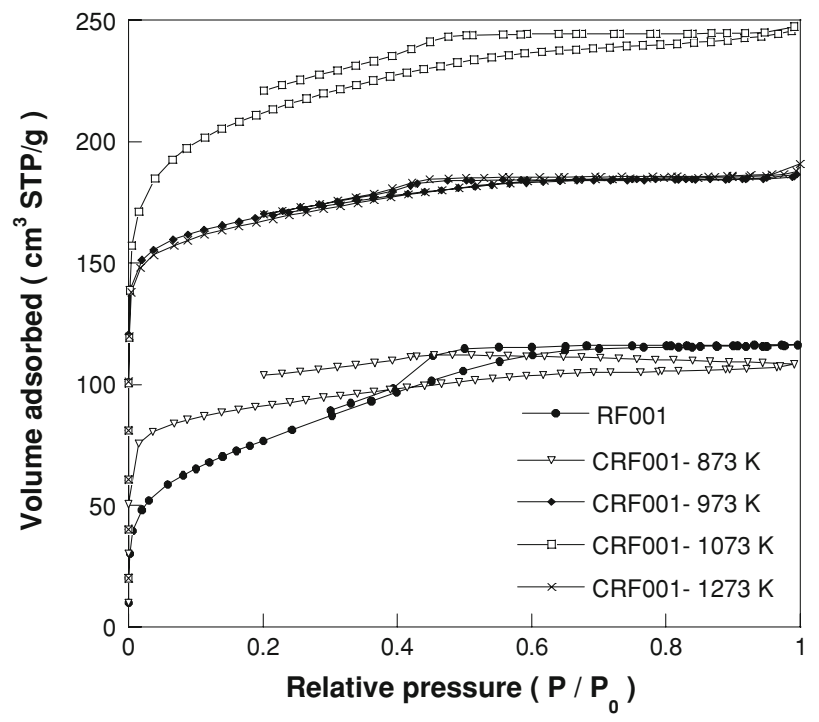

Fig. $3 \mathrm{~N}_{2}$ adsorption-desorption isotherms at $77 \mathrm{~K}$ for RF001 and CRF001 samples

carbon aerogels decreased which shows a decrease in the pore volume of the carbon aerogel. This is probably due to the collapse of the porous structure at high temperatures. Changes in the pore parameters of the carbon aerogels with heat treatment temperatures are listed in Table 2.

The data given in Table 2 shows that both total surface area and total pore volume of the carbon aerogels increase with carbonization temperature for temperatures below $1073 \mathrm{~K}$. Heat treatment of carbon aerogel above $1073 \mathrm{~K}$ decreases both surface area and total pore volume. Carbon aerogel prepared at $1073 \mathrm{~K}$ showed the maximum BET surface area and total pore volume. These results show that a temperature of $1073 \mathrm{~K}$ is the most effective for the development of the pore structure of the gel.

Figure 4 shows the pore size distribution curves for RF001 aerogel and CRF001 carbon aerogels prepared at different temperatures. The PSD curves show that carbonization process decreases volume of pores for pores with diameters in the range of 3-10 $\mathrm{nm}$ significantly. It can be seen that the PSD curves are shifted to smaller diameters after carbonization probably due to the shrinkage of the aerogel structure during the carbonization process. Data in Table 2 suggest that decrease in the mesoporosity of the

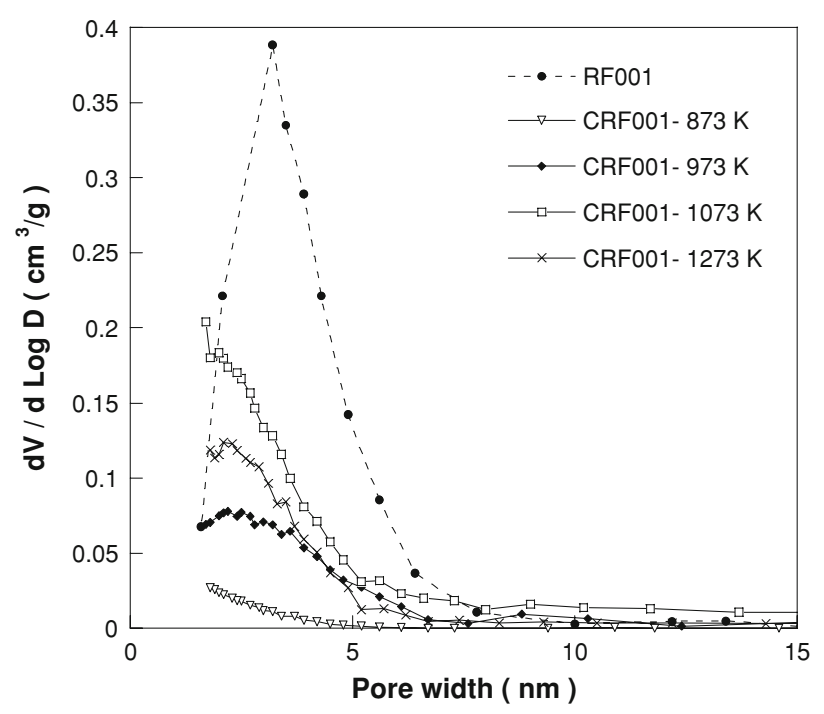

Fig. 4 Pore size distribution of RF001 and CRF001 samples

gel is at the expense of an increase in microporosity during carbonization.

Figure 5 shows the weight loss versus temperature and derivative plots for a dried resorcinol formaldehyde gel. The TGA plot (Fig. 5a) shows that the sample mass does not change with temperatures above $1073 \mathrm{~K}$ and the derivative plot (Fig. 5b) shows that the significant mass losses occur at about 423, 673, and $873 \mathrm{~K}$.

These peaks are related with the desorption of water and carbonization reactions involving breakage of $\mathrm{C}-\mathrm{O}$ bonds at $673 \mathrm{~K}$ and C-H bonds at $873 \mathrm{~K}$, respectively [22]. The TGA shows that above $1073 \mathrm{~K}$ there is no further weight loss.

Since we have established that $1073 \mathrm{~K}$ is the optimum temperature for porosity, the effect of $\mathrm{R} / \mathrm{C}$ ratio on pore structure of carbon aerogels can be investigated.

\section{Effect of R/C ratio on pore structure of carbon aerogels}

The adsorption-desorption isotherms of nitrogen at $77 \mathrm{~K}$ on carbons prepared from aerogels with different $\mathrm{R} / \mathrm{C}$ ratios at $1073 \mathrm{~K}$ are shown in Fig. 6. The isotherms for CRF001 carbon $(\mathrm{R} / \mathrm{C}=100)$ show a type $\mathrm{I}$ isotherm, indicating that this sample is microporous [19, 20]. The initial part of isotherm shows micropore filling and the low

Table 2 Surface characterization of the RF001 aerogel and CRF001 carbon aerogels

\begin{tabular}{lclllllll}
\hline Samples & Temperature $(\mathrm{K})$ & $S_{\text {BET }}\left(\mathrm{m}^{2} / \mathrm{g}\right)$ & $V_{\text {total }}\left(\mathrm{cm}^{3} / \mathrm{g}\right)$ & $V_{\text {micro }}\left(\mathrm{cm}^{3} / \mathrm{g}\right)$ & $V_{\text {meso }}\left(\mathrm{cm}^{3} / \mathrm{g}\right)$ & $\% V_{\text {micro }}$ & $\% V_{\text {meso }}$ & $D_{\text {avg }}(\mathrm{nm})$ \\
\hline RF001 & - & 278 & 0.1797 & 0.1189 & 0.0608 & 66 & 34 & 2.58 \\
CRF001-873 & 873 & 286 & 0.1870 & 0.1484 & 0.0386 & 79 & 21 & 2.33 \\
CRF001-973 & 973 & 524 & 0.2874 & 0.2625 & 0.0249 & 91 & 9 & 2.27 \\
CRF001-1073 & 1073 & 669 & 0.3800 & 0.3300 & 0.0500 & 86 & 14 & 2.19 \\
CRF001-1273 & 1273 & 520 & 0.2905 & 0.2603 & 0.0302 & 89 & 11 & 2.23 \\
\hline
\end{tabular}


Fig. 5 Thermogravimetric analysis of a dried RF aerogel. a Weight $\%$ versus carbonization temperature, $\mathbf{b}$ derivative thermogravimetry
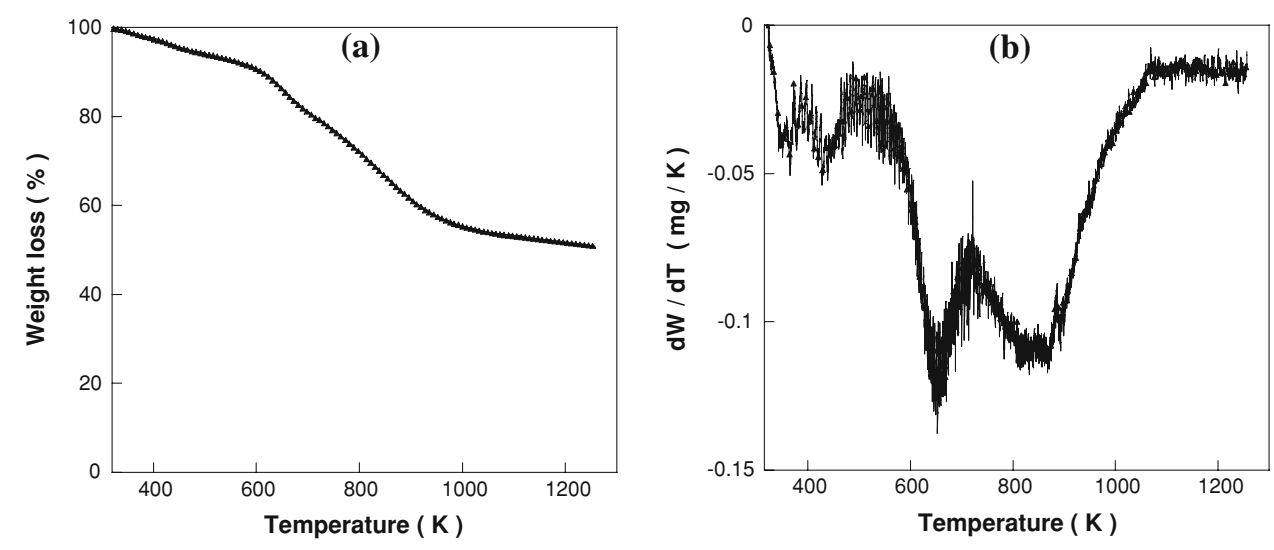

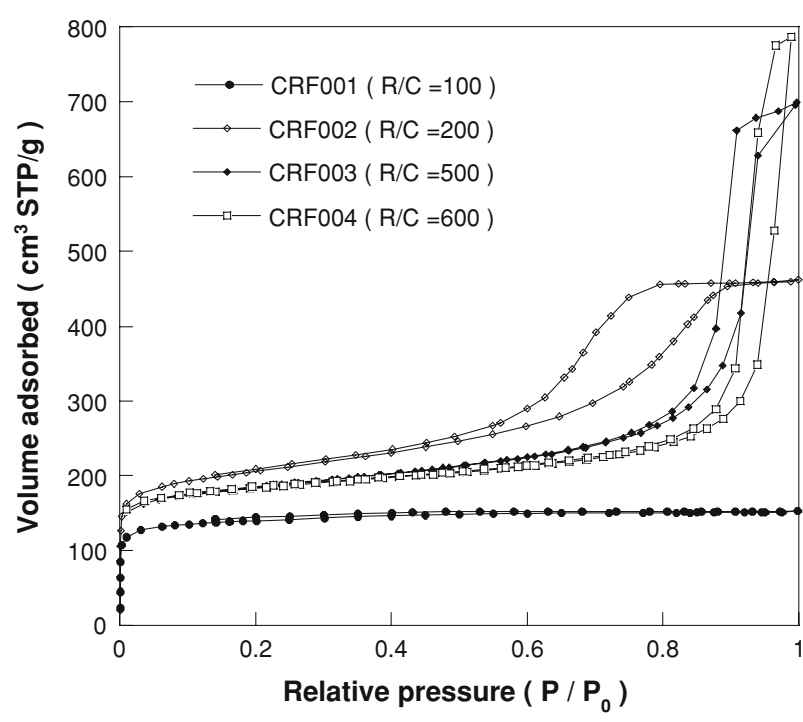

Fig. $6 \mathrm{~N}_{2}$ adsorption-desorption isotherms at $77 \mathrm{~K}$ for carbons with different $\mathrm{R} / \mathrm{C}$ ratios

slope of the plateau is due to multilayer adsorption on the external surface.

For CRF002 sample $(\mathrm{R} / \mathrm{C}=200)$ the initial region of the isotherms $\left(P / P_{0}<0.01\right)$ experience a sharp rise which is indicative of micropores in the sample. The hysteresis loop in the $P / P_{0}$ range $0.4-0.8$ is indicative of mesoporosity in the structure of the carbon in addition to the presence of micropores.

In the case of CRF003 sample $(\mathrm{R} / \mathrm{C}=500)$ hysteresis loop for filling and emptying of mesopores is shifted to a higher $P / P_{0}$ range (i.e., $\left.0.7-1.0\right)$ which is associated with the presence of mesopores with larger diameters in the structure. For CRF004 carbon with R/C ratio of 600 hysteresis loop is in the $P / P_{0}$ range $0.82-1.0$ indicative of even larger mesopores in the carbon structure.

Figure 7 shows the PSD curves for the carbon samples. Sample CRF001 exhibits a micropore peak at the pore diameter of $2 \mathrm{~nm}$ and there is a shift of pore size distribution to pores with larger diameters as $\mathrm{R} / \mathrm{C}$ ratio increases.

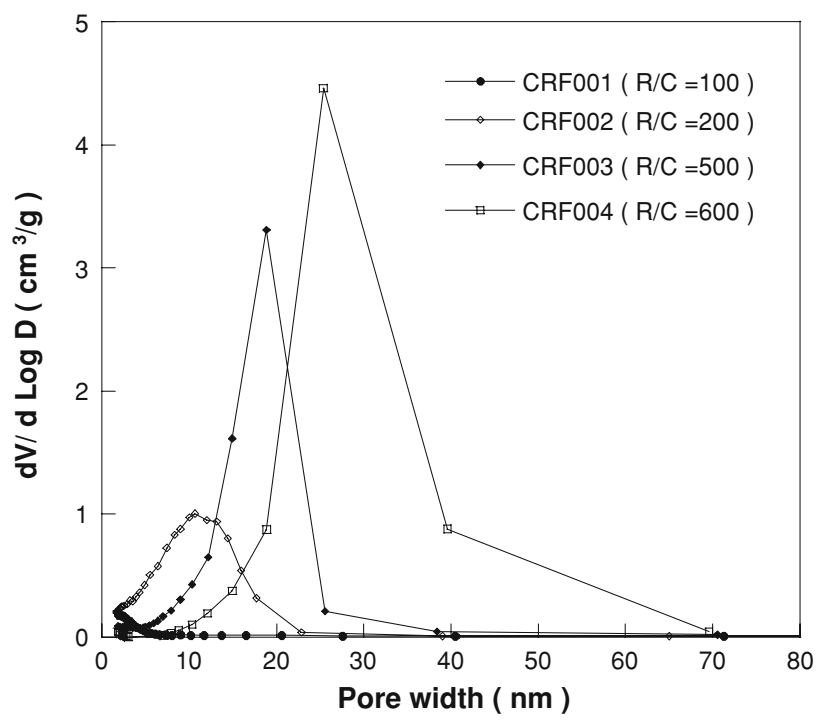

Fig. 7 Pore size distribution of carbons with different R/C ratios

The related porous parameters are listed in Table 3. It can be observed that with increase of the molar ratio of resorcinol to catalyst (R/C ratio) from 100 to 600 in the initial gel precursors both the total pore volume and the average pore diameter of the resultant carbon aerogels increase from 0.38 to $1.2779 \mathrm{~cm}^{3} \mathrm{~g}^{-1}$ and 2.19 to $25.27 \mathrm{~nm}$, respectively. The PSD curves for all carbon aerogels are shifted to pores with smaller diameters (Fig. 7) in comparison to PSD curves for the corresponding aerogels (Fig. 2). This is due to either the shrinkage of the gel structure or creation of some micropores in the carbon structure during the carbonization.

Carbon aerogels prepared in this work possess different porous structures ranging from microporous structure, mesopores structure with small mesopores, and mesopores structure with large mesopores. These results indicate that the porous structure and especially the pore volume and the pore size distribution of the aerogels and carbon aerogels can be adjusted by changing the $\mathrm{R} / \mathrm{C}$ ratio of the gel precursors. 
Table 3 Porous parameters of carbon samples

\begin{tabular}{lllllllll}
\hline Samples & $\mathrm{R} / \mathrm{C}$ & $S_{\text {BET }}\left(\mathrm{m}^{2} / \mathrm{g}\right)$ & $V_{\text {total }}\left(\mathrm{cm}^{3} / \mathrm{g}\right)$ & $V_{\text {micro }}\left(\mathrm{cm}^{3} / \mathrm{g}\right)$ & $V_{\text {meso }}\left(\mathrm{cm}^{3} / \mathrm{g}\right)$ & $\% V_{\text {micro }}$ & $\% V_{\text {meso }}$ & $D_{\text {avg }}(\mathrm{nm})$ \\
\hline CRF001 & 100 & 669 & 0.3800 & 0.3300 & 0.0500 & 86 & 14 & 2.19 \\
CRF002 & 200 & 702 & 0.714 & 0.183 & 0.531 & 26 & 74 \\
CRF003 & 500 & 647 & 1.2245 & 0.2101 & 1.0144 & 17 & 83 \\
CRF004 & 600 & 576 & 1.2779 & 0.2012 & 1.0767 & 16 & 84 & 21.65 \\
\hline
\end{tabular}

Effect of activation on the porous structure of the carbon aerogels

Adsorption-desorption isotherms of nitrogen at $77 \mathrm{~K}$ for CRF002 carbon aerogel and ACRF002 activated carbon aerogels obtained by $\mathrm{CO}_{2}$ activation of CRF002 carbon aerogel at different temperatures for varying times are shown in Fig. 8. Activated carbons are named as ACRF002- $x$ where $x$ is activation temperature.

The adsorption-desorption isotherms show a steep increase in the amount of gas adsorbed at $P / P_{0}<0.01$. This shows that large quantity of micropores have been introduced into the carbon aerogel after physical activation [15]. This might be due to the creation of new micropores by oxidation of certain structural components and also opening of previously inaccessible pores [23].

Hysteresis loops in the $P / P_{0}$ range $0.4-0.9$ are indicative of mesoporosity in carbons. The lower part of the hysteresis loops represent the filling of the mesopores while the upper parts represent the emptying of the mesopores [19, 20]. It can be observed that hysteresis loops for activated carbons shift vertically to higher adsorbed volumes at higher activation temperatures. This means that increasing

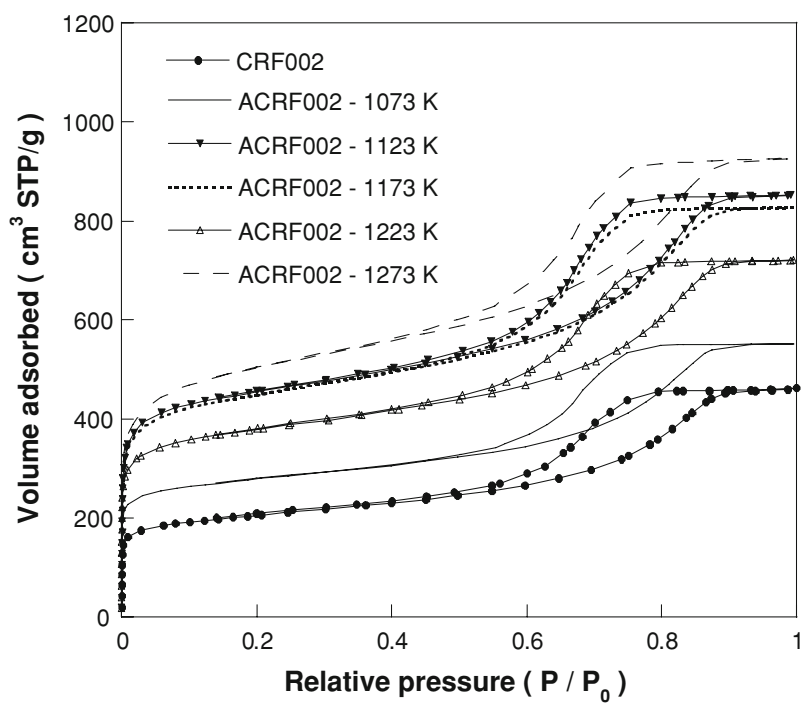

Fig. $8 \mathrm{~N}_{2}$ adsorption-desorption isotherms at $77 \mathrm{~K}$ for ACRF002 carbons at various temperatures the degree of burn off increases the amount of gas adsorbed by sample which is indicative of the development of porosity in the carbon structure.

It is noteworthy that for all isotherms shown in Fig. 8 hysteresis loops are located almost over the same $P / P_{0}$ range (i.e., 0.4-0.9). This shows that the activation of CRF002 sample does not affect the size of pores and pore size distribution significantly. Figure 9 also shows that for all samples, the PSD curves are centered at the same pore diameter range (i.e., around $10 \mathrm{~nm}$ ) indicating all carbon samples are mainly mesoporous materials and possess similar pore sizes and pore size distributions.

Porous parameters of carbon samples activated at different degrees of burn off are given in Table 4. It can be observed that although the average diameters of pores for all samples are similar, there is a significant increase in pore volume of the samples with burn off.

Table 4 shows that the degree of burn off is higher at higher temperatures thus activation at higher temperatures causes more porosity development and larger pore volume in the carbon structure.

Figure 9 shows that this porosity development mainly takes place in the range of small mesopores (i.e., pore

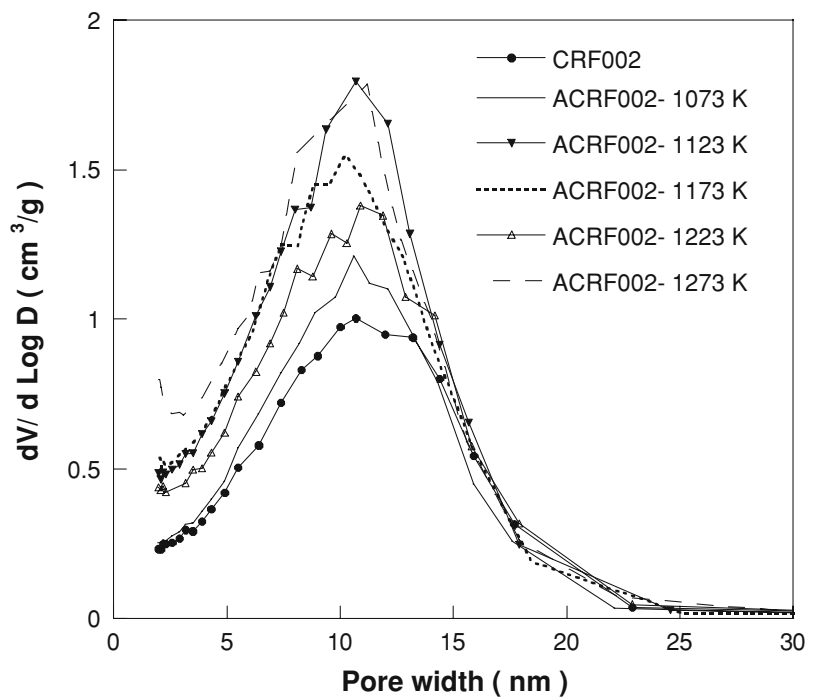

Fig. 9 Pore size distribution of ACRF002 carbons at various temperatures 
Table 4 Porous parameters of CRF002 carbon samples activated at different degrees of burn off

\begin{tabular}{lcllllllll}
\hline Samples & Time $(\mathrm{min})$ & Burn off $\%$ & $S_{\text {BET }}\left(\mathrm{m}^{2} / \mathrm{g}\right)$ & $V_{\text {total }}\left(\mathrm{cm}^{3} / \mathrm{g}\right)$ & $V_{\text {micro }}\left(\mathrm{cm}^{3} / \mathrm{g}\right)$ & $V_{\text {meso }}\left(\mathrm{cm}^{3} / \mathrm{g}\right)$ & $\% V_{\text {micro }}$ & $\% V_{\text {meso }}$ & $D_{\text {avg }}(\mathrm{nm})$ \\
\hline CRF002 & - & 0 & 702 & 0.714 & 0.183 & 0.531 & 26 & 74 & 6.59 \\
ACRF002-1073 K & 180 & 15.72 & 946 & 0.855 & 0.282 & 0.573 & 33 & 67 & 6.47 \\
ACRF002-1123 K & 120 & 43.76 & 1545 & 1.320 & 0.450 & 0.87 & 31 & 69 & 6.10 \\
ACRF002-1173 K & 60 & 49.82 & 1531 & 1.282 & 0.431 & 0.851 & 34 & 66 & 5.85 \\
ACRF002-1223 K & 30 & 65.40 & 1290 & 1.115 & 0.369 & 0.746 & 33 & 67 & 6.15 \\
ACRF002-1273 K & 20 & 67.00 & 1725 & 1.434 & 0.427 & 1.007 & 30 & 70 & 5.60 \\
\hline
\end{tabular}

diameter $\leq 10 \mathrm{~nm}$ ). According to these results, increase in the degree of burn off increases the pore volume, without affecting the mean pore diameter probably due to the creation of more micropores, widening of some micropores, and also opening of more mesopores. It is noteworthy that the degree of burn off increases with activation temperature and time resulting in a significant weight loss in carbons.

In order to prepare carbon samples with larger mesopores and higher pore volumes, CRF003 carbon is activated at different temperatures and varying times. Activated carbons are named as ACRF003- $x$ where $x$ is activation temperature. The corresponding $\mathrm{N}_{2}$ adsorption-desorption isotherms are shown in Fig. 10. These isotherms show that the higher the degree of burn off, the greater is the amount of adsorption.

Figure 11 shows that such an activation treatment results in activated carbons with high pore volumes and average pore diameters of around $15 \mathrm{~nm}$. Porosity development takes place in the range of large pores (i.e., pore diameter $\sim 20 \mathrm{~nm}$ ).

Data given in Table 5 show that activation at $1323 \mathrm{~K}$ produces a large increase in surface characteristics such as

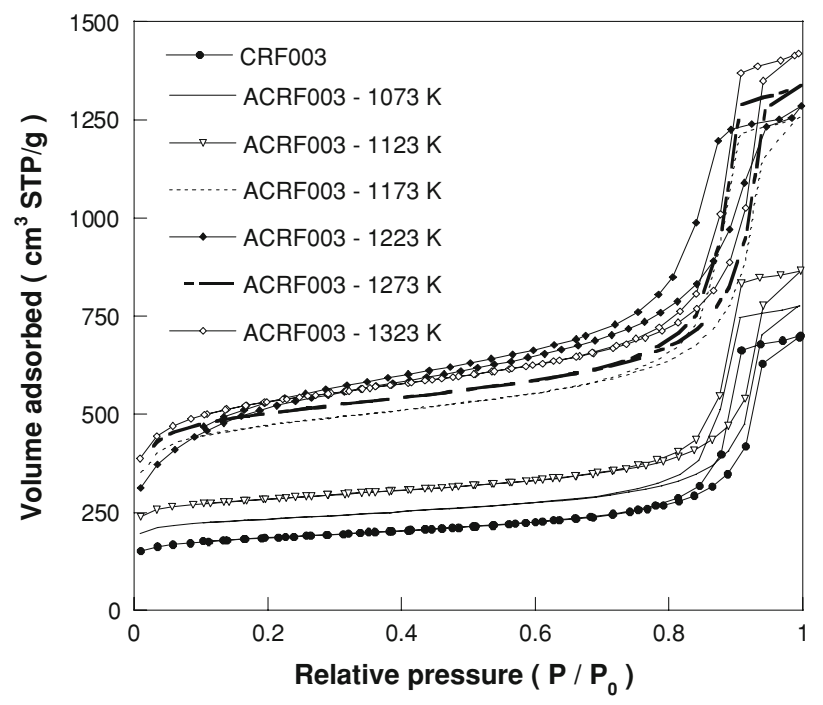

Fig. $10 \mathrm{~N}_{2}$ adsorption-desorption isotherms at $77 \mathrm{~K}$ for ACRF003 carbons at various temperatures

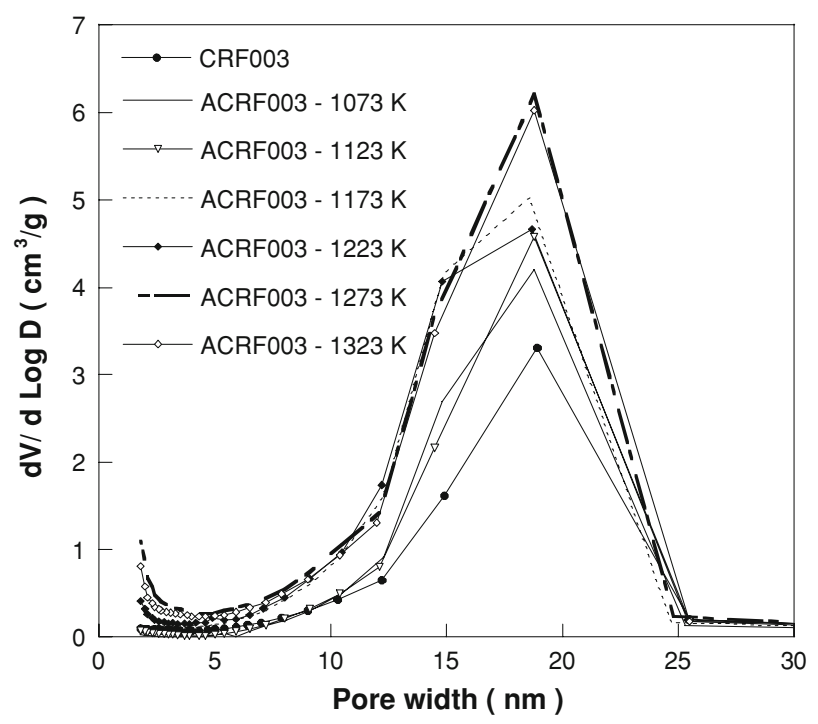

Fig. 11 Pore size distribution of ACRF003 carbons at various temperatures

total and mesopore volumes and BET surface area. This sample has the largest total pore volume $\left(2.195 \mathrm{~cm}^{3} / \mathrm{g}\right)$ and the largest mesopore volume $\left(1.732 \mathrm{~cm}^{3} / \mathrm{g}\right)$ of all activated CRF003 carbons.

\section{Conclusions}

The recent development of industrial technology provides new applications for porous carbons in the fields of adsorption, gas storage, separation and purification, catalyst supports, electrodes for lithium batteries and electric double layer supercapacitors, etc.

In this study the pore structure of resorcinol-formaldehyde gels and porous carbon aerogels was controlled by changing the $\mathrm{R} / \mathrm{C}$ ratio and carbonization and activation parameters. The aim of this modification was to prepare porous carbons with controlled pore structure designed for different applications. Characterization of the resultant materials based on pore size information obtained from nitrogen adsorption/desorption isotherms shows that: 
Table 5 Porous parameters of CRF003 carbon samples activated at different degrees of burn off

\begin{tabular}{|c|c|c|c|c|c|c|c|c|c|}
\hline Samples & Time $(\min )$ & Burn off $\%$ & $S_{\text {BET }}\left(\mathrm{m}^{2} / \mathrm{g}\right)$ & $V_{\text {total }}\left(\mathrm{cm}^{3} / \mathrm{g}\right)$ & $V_{\text {micro }}\left(\mathrm{cm}^{3} / \mathrm{g}\right)$ & $V_{\text {meso }}\left(\mathrm{cm}^{3} / \mathrm{g}\right)$ & $\% V_{\text {micro }}$ & $\% V_{\text {meso }}$ & $D_{\text {avg }}(\mathrm{nm})$ \\
\hline CRF003 & - & 0 & 647 & 1.2245 & 0.2101 & 1.0144 & 17 & 83 & 21.65 \\
\hline ACRF003-1073 K & 150 & 9.7 & 732 & 1.200 & 0.253 & 0.947 & 21 & 79 & 16.77 \\
\hline ACRF003-1123 K & 125 & 21 & 891 & 1.336 & 0.313 & 1.023 & 24 & 76 & 15.93 \\
\hline ACRF003-1173 K & 120 & 54 & 1497 & 1.942 & 0.448 & 1.494 & 23 & 77 & 15.43 \\
\hline ACRF003-1223 K & 60 & 58 & 1506 & 1.965 & 0.434 & 1.531 & 22 & 78 & 15.01 \\
\hline ACRF003-1273 K & 30 & 65 & 1585 & 2.075 & 0.488 & 1.587 & 23 & 77 & 14.76 \\
\hline ACRF003-1323 K & 20 & 67 & 1687 & 2.195 & 0.463 & 1.732 & 21 & 79 & 14.23 \\
\hline
\end{tabular}

1. $\mathrm{R} / \mathrm{C}$ ratio is the dominant factor that controls the surface area, total pore volume, and mechanical properties of RF aerogels. There is a development in mesoporosity of aerogels with increasing $\mathrm{R} / \mathrm{C}$ ratio. This might be due to the effect of $\mathrm{R} / \mathrm{C}$ ratio on the interparticle cross-link density that influences the microscopic structure of aerogels remarkably [24].

When resorcinol reacts with formaldehyde in the presence of a catalyst, the catalyst instigates the formation of resorcinol anions which are more reactive toward the addition of formaldehyde compared to the uncharged resorcinol molecules [25]. The formation of the resorcinol anion represents the beginning of the RF cluster formation which is responsible for the cross linkage. Cross links are formed upon polycondensation of resorcinol with formaldehyde and it occurs between aromatic rings due to polycondensation.

RF aerogels have a highly crosslinked structure, that is an interconnected spherical particle structure [21]. The particle size increases with $\mathrm{R} / \mathrm{C}$ ratio. The size and number of RF clusters formed during the gelation process depends on the $\mathrm{R} / \mathrm{C}$ ratio. High catalyst conditions (i.e., low $\mathrm{R} / \mathrm{C}$ ratios) results in formation of small particles leading to microporous structure and low catalyst conditions (i.e., high $\mathrm{R} / \mathrm{C}$ ratios) results in formation of larger particles leading to the development of mesoporosity in the gel structure.

2. $\mathrm{R} / \mathrm{C}$ ratio manifests itself as a controlling parameter in the structure and properties of carbon aerogels. Although the porous structure of the carbon aerogel is related to that of the gel precursor, the carbonization temperature impacts the microstructure of the resultant carbons and some pore transformations take place during carbonization. Since the pore size distribution curves for carbon aerogels are shifted to the left compared with those of RF aerogels, it can be seen that pore structure of the gels are shrunk by carbonization and increase in the amount of nitrogen adsorbed at low relative pressures shown on the isotherms of carbons indicates the formation of micropores. Carbonization causes an increase in mesoporosity, microporosity, and BET surface area.
3. $\mathrm{CO}_{2}$ activation results in an increase in the number of both micropores and mesopores, indicative of creation of more porosity in the structure of the carbon.

Increase in the degree of burn off results in higher pore volumes (the maximum value: $2.195 \mathrm{~cm}^{3} \mathrm{~g}^{-1}$ ) and BET surface areas (the maximum value: $1725 \mathrm{~m}^{2} \mathrm{~g}^{-1}$ ) without changing the basic structure of the carbons such as average pore size and pore size distribution.

Acknowledgement We would like to thank the EPSRC for funding as part of the Supergen Energy Storage Consortium (grant code EP/D031672/1).

\section{References}

1. Sircar S, Golden TC, Rao MB (1996) Carbon 34:1

2. Yamamoto T, Endo A, Ohmori T, Nakaiwa M (2004) Carbon 42:671

3. Frackowiak E, Beguin F (2001) Carbon 39:937

4. Li W, Reichenauer G, Fricke J (2002) Carbon 40:2955

5. Pekala RW, Farmer JC, Alviso CT, Tran TD, Mayer ST, Miller JM, Dunn B (1998) J Non-Cryst Solids 225:74

6. Job N, Heinrichs B, Lambert S, Pirard JP, Colomer JF, Vertruyen B, Marien J (2006) AIChE J 52:2663

7. Gilbert MT, Knox JH, Kaur B (1982) Chromatographia 16:138

8. Feaver A, Cao G (2006) Carbon 44:587

9. Maldonado-Hodar FJ, Ferro-Garcia MA, Rivera-Utrilla J, Moreno-Castilla C (1999) Carbon 37:1199

10. Pierre AC, Pajonk GM (2002) Chem Rev 102:4243

11. Fung AWP, Wang ZH, Lu K (1993) J Mater Res 8:1875

12. Ruben GC, Pekala RW, Tillotson TM, Hrubesh LW (1992) J Mater Sci 27:4341. doi:10.1007/BF00541564

13. Job N, Pirard R, Marien J, Pirard JP (2004) Carbon 42:619

14. Reynolds GAM, Fung AWP, Wang ZH, Dresselhaus MS, Pekala RW (1995) J Non-Cryst Solids 188:27

15. Kruk M, Jaroniec M, Gadkaree KP (1997) J Colloid Interface Sci 192:250

16. Brinker CJ, Scherer GW (1990) Sol-gel science: the physics and chemistry of sol-gel processing. Academic Press, London

17. Pekala RW (1989) J Mater Sci 24:3221. doi:10.1007/BF01139044

18. Pekala RW, Schaefer W (1993) Macromolecules 26:5487

19. Gregg SJ, Sing KSW (1967) Adsorption, surface area and porosity. Academic Press, New York

20. Rouquerol F, Rouquerol J, Sing K (1999) Adsorption by powders and porous solids, principles, methodology and applications. Academic Press, New York 
21. Tamon H, Ishizaka H, Mikami M, Okazaki M (1997) Carbon 35:791

22. Lin C, Pitter JA (1997) Carbon 35:1271

23. Marsh H, Rand B (1971) Carbon 9:47
24. Pekala RW, Alviso CT, LeMay JD (1990) J Non-Cryst Solids 125:67

25. Li WC, Lu AH, Guo SC (2001) Carbon 39:1989 